\title{
Prognostic Significance of Solid and Micropapillary Components in Invasive Lung Adenocarcinomas Measuring $\leq 3 \mathrm{~cm}$
}

\author{
YUKI MATSUOKA ${ }^{1,2}$, YOHEI YURUGI ${ }^{1,2}$, YUZO TAKAGI ${ }^{2}$, MAKOTO WAKAHARA ${ }^{1,2}$, \\ YASUAKI KUBOUCHI ${ }^{2}$, TOMOHIKO SAKABE ${ }^{1}$, TOMOHIRO HARUKI ${ }^{2}$, KUNIO ARAKI $^{2}$, \\ YUJI TANIGUCHI ${ }^{2}$, HIROSHIGE NAKAMURA ${ }^{1}$ and YOSHIHISA UMEKITA ${ }^{1}$ \\ ${ }^{1}$ Division of Organ Pathology, Department of Microbiology and Pathology, and \\ ${ }^{2}$ Division of General Thoracic Surgery, Department of Surgery, \\ Faculty of Medicine, Tottori University, Tottori, Japan
}

\begin{abstract}
Background/Aim: We aimed to analyze the clinical impact of solid and micropapillary components in a series of Japanese patients resected for $\leq 3 \mathrm{~cm}$ lung adenocarcinoma. Patients and Methods: A total of 115 patients with $\leq 3 \mathrm{~cm}$ lung adenocarcinomas were reviewed and classified according to the American Thoracic Society and the European Respiratory Society classification. The presence of solid $(S+)$ or micropapillary component $(\mathrm{MP}+)$ was defined when the component constituted $\geq 1 \%$ of the entire tumor. The impact of these components on disease-free (DFS) and disease-specific (DSS) survival was analyzed. Results: Thirty (26.1\%) cases with S+ and 27 (23.5\%) with $M P+$ were identified, and multivariate analysis indicated that $S+$ status significantly reduced the duration of DFS and DSS. In 86 patients of acinar-and papillary-predominant subgroups, $S+$ and/or $M P+$ had the most significant effect on DFS and DSS by multivariate analysis. Conclusion: $S+$ and/or MP+ status predict worse prognosis in patients with acinar-and papillary-predominant lung adenocarcinoma.
\end{abstract}

Lung cancer is the leading cause of cancer-related death worldwide, including in Japan (1). The proportion of lung adenocarcinomas among all lung cancer cases has increased over the past several decades, and lung adenocarcinoma is now the most frequently diagnosed histological subtype of non-small cell lung cancer (NSCLC) in most countries (2). In

Correspondence to: Yoshihisa Umekita, MD, Ph.D., Division of Organ Pathology, Department of Pathology, Faculty of Medicine, Tottori University, 86 Nishicho, Yonago, Tottori 683-8503, Japan. Tel: +81 859386053, Fax: +81859386050, e-mail: yume@med.tottoriu.ac.jp

Key Words: Adenocarcinoma, lung cancer, solid, micropapillary component.
2011, a new classification of lung adenocarcinoma was published by the International Association for the Study of Lung Cancer, the American Thoracic Society and the European Respiratory Society (IASLC/ATS//ERS) (3). In this classification, five distinctive subtypes of invasive lung adenocarcinoma were defined in association with prognosis: the lepidic subtype (as favorable prognosis), the acinar and papillary subtypes (as intermediate), and the micropapillary and solid subtypes (as poor). Since that new classification was issued, the association between the predominant subtype and prognosis has been validated by many studies in which the solid- and micropapillary-predominant subtypes conferred poor prognosis compared to the other three subtypes (4-10). According to the IASLC/ATS/ERS classification, all subtypes are listed semi-quantitatively in 5\% increments, and the predominant component is defined as the pattern involving the greatest proportion of the tumor. Patterns constituting $<5 \%$ of the entire tumor are thus usually overlooked. Few studies have investigated the clinical impact of nonpredominant components of micropapillary or solid patterns constituting $<5 \%$ of the entire tumor (11-13). To our knowledge, only one report focused on the clinical significance of a solid component constituting $<5 \%$ of the entire invasive lung adenocarcinoma (13), and it remains to be determined whether these components could be a predictor of worse prognosis in patients with tumors in the acinar- and papillary-predominant subgroups.

The improvement of imaging techniques has made possible the detection of smaller and earlier-stage lung cancer; however, the long-term survival rate of patients with NSCLC is still poor, even when their tumors are completely resected at an early stage $(14,15)$. To our knowledge, few studies have used the IASLC/ATS/ERS classification to focus on the classification's prognostic impact in patients with early-stage lung adenocarcinoma $(6,7,16-18)$. The aim of our present study was, thus, to clarify the prognostic 
impact of solid and/or micropapillary components ( $\geq 1 \%)$ in patients with acinar- and papillary-predominant tumors and patients with early-stage lung adenocarcinoma.

\section{Patients and Methods}

Patients and tissue samples. Overall, 167 consecutive patients who underwent curative-intent surgery at Tottori University Hospital (Tottori, Japan) and were diagnosed as having a primary lung adenocarcinoma measuring $\leq 3 \mathrm{~cm}$ between January 2005 and December 2008 were included in this study. No patient received neoadjuvant chemotherapy or radiation therapy. Fourteen cases were excluded because of non-curative operation in 11 cases, unavailable tumor specimen in one case, and surgery-related death in two cases. Adenocarcinoma in situ and minimally invasive adenocarcinoma in 30 cases were excluded because of the extremely favorable prognosis $(4,5)$. Eight cases of invasive mucinous adenocarcinoma were also excluded. Thus, 115 patients were included in the present analysis. The patients' clinicopathological data were obtained from their hospital medical records.

Histopathological evaluation. The pathological diagnosis was performed using hematoxylin and eosin-stained sections according to the criteria of the current World Health Organization classification for lung cancer (2). The following histopathological factors were evaluated: tumor differentiation, tumor size, lymph node metastasis and pleural invasion. Pleural invasion was evaluated using Elastica van Gieson staining. Tumor stage was determined based on the seventh tumor-node-metastasis (TNM) classification of lung cancer (19). All tumor slides were reviewed by two pathologists (YM and YU) without knowledge of any clinical data, and the slides were classified into five predominant subtypes, lepidic, acinar, papillary, micropapillary and solid, according to the IASLC/ATS/ERS classification system (3). For cases in which the two pathologists disagreed, a discussion was held using a multiple-headed microscope for the slide examination until a consensus was achieved. Cases with a solid component occupying $\geq 1 \%$ of the entire tumor were defined as positive for solid component ( $\mathrm{S}+$ ), and cases with a micropapillary component occupying $\geq 1 \%$ of the entire tumor were defined as positive for micropapillary component (MP+).

Survival analyses. For the survival analysis, cancer relapse (local recurrence or distant recurrence) and death were used to calculate the disease-free survival (DFS) and the disease-specific survival (DSS), respectively. The DFS and DSS values were calculated from the date of the patient's initial surgery to the date of clinical or pathological relapse or disease-specific death. The cases of the patients who were alive were censored at the time of their last follow-up visit. The cases of the patients who died from a cause unrelated to their lung cancer or for whom the cause of death was not entirely clear were censored for the purposes of survival analysis.

Statistical analyses. All statistical analyses were performed using the Statistical Package for Social Sciences version 21 (IBM SPSS Statistics, IBM, Armonk, NY, USA). We evaluated the association between the presence of solid or micropapillary component and clinicopathological parameters by performing non-parametric tests. The chi-square test was used when there were two categorical variables of interest. Survival curves were computed according to the Kaplan-Meier method, and we tested differences in DFS and DSS using the log-rank test. We used the Cox regression hazard model to evaluate the effect of various factors on DFS and DSS in order to justify the independent prognostic value. All tests of significance were two-sided, and differences were considered significant at a $p$-value less than 0.05 .

\section{Results}

Correlation of between the predominant patterns and prognosis. Among the 115 patients, eight (7.0\%) and 19 (16.5\%) patients experienced locoregional recurrence and distant recurrence, respectively. Seventeen patients (14.8\%) died of lung cancer progression and nine patients (7.8\%) died of other causes such as gastric, colon, or pancreatic cancer, pneumonia, interstitial pneumonia and trauma. The median clinical follow-up time was 78 months (range $=1-118$ months). The patient's characteristics and distribution of each subtype according to the IASLC/ATS/ERS classification system are shown in Table I.

The survival curves for the patients are shown in Figure 1. The 5-year DFS rates for the patients in the lepidic-, acinar-, papillary- and solid-predominant subgroups were $100 \%, 64.2 \%, 80.0 \%$ and $60.0 \%$, and the 5-year DSS rates were $100 \%, 87.6 \%, 96.0 \%$ and $86.2 \%$, respectively.

Relationship between $S+$ status and clinicopathlogical factors or prognosis. Thirty cases $(26.1 \%)$ with S+ status were recorded, and $\mathrm{S}+$ status was significantly correlated with higher pathological stage $(p=0.01)$ and presence of lymph node metastasis $(p=0.002)$ (Table I). The survival curves for these patients are shown in Figure 2. The 5-year DFS rates of $\mathrm{S}+$ and $\mathrm{S}-$ subgroups were $44.8 \%$ [95\% confidence interval $(\mathrm{CI})=6.8-62.8 \%]$ and $80.4 \%(95 \%$ $\mathrm{CI}=71.8-89.0 \%)$, respectively, and the 5-year DSS rates were 71.5\% (95\% CI $=54.6-88.4 \%)$ and $97.4 \%(95 \% \mathrm{CI}=93.9-$ $100.9 \%$ ), respectively (Figure 2A and B). The multivariate analysis revealed that $\mathrm{S}+$ status had a significantly negative effect on both the DFS and DSS ( $p=0.006$ and $p=0.003$, respectively), as well as the pathological stage ( $p=0.014$ and $p=0.006$, respectively) (Table II).

Relationship between MP+ status and clinicopathological factors or prognosis. Twenty-seven cases (23.5\%) with MP+ status were identified, and MP+ status was significantly correlated with higher pathological stage $(p=0.003)$ and the presence of lymph node metastasis $(p=0.001)$ (Table I). The 5-year DFS rates of MP+ and MP- subgroups were 51.9\% (95\% $\mathrm{CI}=33.1-70.7 \%)$ and $77.3 \%$ (95\% $\mathrm{CI}=68.3-86.3 \%)$, respectively, and the 5-year DSS rates were $81.3 \%(95 \%$ $\mathrm{CI}=66.6-96.0 \%) \quad$ and $94.1 \% \quad(95 \% \quad \mathrm{C}=89.0-99.2 \%)$, respectively (Figure $2 \mathrm{C}$ and $\mathrm{D}$ ). Multivariate analysis showed that the MP+ subgroup had a significantly shorter DFS $(p=0.012)$ but not DSS $(p=0.430)$ (Table II). 
Table I. Association between solid or micropapillary components and clinicopathological characteristics of patients with lung adenocarcinoma.

\begin{tabular}{|c|c|c|c|c|c|c|c|}
\hline & \multirow{2}{*}{$\begin{array}{c}\text { Total } \\
(\mathrm{N}=115)\end{array}$} & \multicolumn{2}{|c|}{ Micropapillary component } & \multirow[b]{2}{*}{$p$-Value } & \multicolumn{2}{|c|}{ Solid component } & \multirow[b]{2}{*}{$p$-Value } \\
\hline & & $\begin{array}{l}\text { Negative } \\
(\mathrm{N}=88)\end{array}$ & $\begin{array}{c}\text { Positive } \\
(\mathrm{N}=27)\end{array}$ & & $\begin{array}{c}\text { Negative } \\
(\mathrm{N}=85)\end{array}$ & $\begin{array}{l}\text { Positive } \\
(\mathrm{N}=30)\end{array}$ & \\
\hline \multicolumn{8}{|l|}{ Age (years) } \\
\hline$\leq 60$ & $22(19)$ & $14(16)$ & $8(30)$ & \multirow[t]{2}{*}{0.113} & $16(19)$ & $6(20)$ & \multirow[t]{2}{*}{0.888} \\
\hline$>60$ & $93(81)$ & $74(84)$ & $19(70)$ & & $69(81)$ & $24(80)$ & \\
\hline \multicolumn{8}{|l|}{ Gender } \\
\hline Male & $60(52)$ & $46(52)$ & $14(52)$ & \multirow[t]{2}{*}{0.969} & $39(46)$ & $21(70)$ & \multirow[t]{2}{*}{0.023} \\
\hline Female & $55(48)$ & $42(48)$ & $13(48)$ & & $46(54)$ & $9(30)$ & \\
\hline \multicolumn{8}{|l|}{ Smoking history } \\
\hline Ever & $61(53)$ & $46(52)$ & $15(56)$ & \multirow[t]{2}{*}{0.765} & $39(46)$ & $22(73)$ & \multirow[t]{2}{*}{0.010} \\
\hline Never & $54(47)$ & $42(48)$ & $12(44)$ & & $46(54)$ & $8(27)$ & \\
\hline \multicolumn{8}{|l|}{ Tumor size $(\mathrm{cm})$} \\
\hline$\leq 2.0$ & $67(58)$ & $54(61)$ & $13(48)$ & \multirow[t]{2}{*}{0.223} & $53(62)$ & $14(47)$ & \multirow[t]{2}{*}{0.134} \\
\hline$>2.0$ & $48(42)$ & $34(39)$ & $14(52)$ & & $32(38)$ & $16(53)$ & \\
\hline \multicolumn{8}{|l|}{ Pathological stage } \\
\hline $\mathrm{I}$ & $100(87)$ & $81(92)$ & $19(70)$ & \multirow[t]{2}{*}{0.003} & $78(92)$ & $22(73)$ & \multirow[t]{2}{*}{0.010} \\
\hline II-IIIA & $15(13)$ & $7(8)$ & $8(30)$ & & $7(8)$ & $8(27)$ & \\
\hline \multicolumn{8}{|l|}{ Lymph node metastasis } \\
\hline Present & $102(89)$ & $83(94)$ & $19(70)$ & \multirow[t]{2}{*}{0.001} & $80(94)$ & $22(73)$ & \multirow[t]{2}{*}{0.002} \\
\hline Absent & $13(11)$ & $5(6)$ & $8(30)$ & & $5(6)$ & $8(27)$ & \\
\hline \multicolumn{8}{|l|}{ Pleural invasion } \\
\hline Present & $97(84)$ & $76(86)$ & $21(78)$ & \multirow[t]{2}{*}{0.283} & $74(87)$ & $23(77)$ & \multirow[t]{2}{*}{0.178} \\
\hline Absent & $18(16)$ & $12(14)$ & $6(22)$ & & $11(13)$ & $7(23)$ & \\
\hline \multicolumn{8}{|l|}{ Extent of resection } \\
\hline Lobectomy & $84(73)$ & $61(69)$ & $23(85)$ & \multirow[t]{2}{*}{0.104} & $61(72)$ & $23(77)$ & \multirow[t]{2}{*}{0.603} \\
\hline Segmentectomy or wedge resection & $31(27)$ & $27(31)$ & $4(15)$ & & $24(28)$ & $7(23)$ & \\
\hline Predominant subtype & & & & & & & \\
\hline Lepidic & $13(11)$ & $13(15)$ & $0(0)$ & & $13(16)$ & $0(0)$ & \\
\hline Acinar & $61(53)$ & $47(53)$ & $14(52)$ & & $53(62)$ & $8(27)$ & \\
\hline Papillary & $25(22)$ & $13(15)$ & $12(25)$ & & $19(22)$ & $6(20)$ & \\
\hline Solid & $16(14)$ & $15(17)$ & $1(3)$ & & $0(0)$ & $16(53)$ & \\
\hline Micropapillary & $0(0)$ & $0(0)$ & $0(0)$ & & $0(0)$ & $0(0)$ & \\
\hline
\end{tabular}

Survival analysis of patients with pathological stage I disease. Among the 100 patients with pathological stage I disease, we identified $22 \mathrm{~S}+$ cases $(22.0 \%)$. These patients had significantly shorter DFS $(p=0.008)$ and DSS $(p=0.011)$ (Figure 3A and B). Nineteen MP+ cases $(19.0 \%)$ were recorded and MP+ status was significantly correlated with a shorter DFS $(p=0.005)$ but not DSS ( $p=0.053$ ) (Figure 3C and D).

Correlation between high-grade component $(S+$ and/or $M P+)$ status and the prognosis in patients of the acinar-and papillary-predominant subgroups. In the 86 patients of acinar- and papillary-predominant subgroups, the 5-year DFS rates of the patients with a high-grade component $(\mathrm{S}+$ or $\mathrm{MP}+)$ and without such a component were $44.1 \%(95 \%$ $\mathrm{CI}=27.4-60.8 \%)$ and $85.7 \% \quad(95 \% \quad \mathrm{CI}=75.9-95.5 \%)$, respectively, and the 5-year DSS rates of these groups were $76.0 \%$ (95\% CI=61.5-80.5\%) and $100 \%$ (95\% CI=92.6$100 \%)$, respectively. Patients with a high-grade component had significantly shorter DFS $(p<0.001)$ and DSS $(p<0.001)$ by log-rank test (Figure $4 \mathrm{~A}$ and $\mathrm{B}$ ). According to the multivariate analysis, the presence of a high-grade component had the most significant effect on DFS (hazard ratio $=5.519$ ) and DSS (hazard ratio=17.963) (Table III).

\section{Discussion}

The reported frequencies of the five predominant subtypes of invasive adenocarcinoma vary (4-11). The major reason for the discrepancy is considered to be interobserver variation (20). In an American cohort of 514 patients with stage I lung adenocarcinoma (4), the frequencies of the lepidic-, acinar-, papillary-, solid- and micropaillarypredominant pattern were $5.6 \%, 45.1 \%, 27.8 \%, 13.0 \%$ and $2.3 \%$, respectively. In our present cohort, the corresponding frequencies were $11 \%, 53 \%, 21.7 \%, 14 \%$ and $0 \%$, respectively. Thus, the frequencies of our cohort were almost 

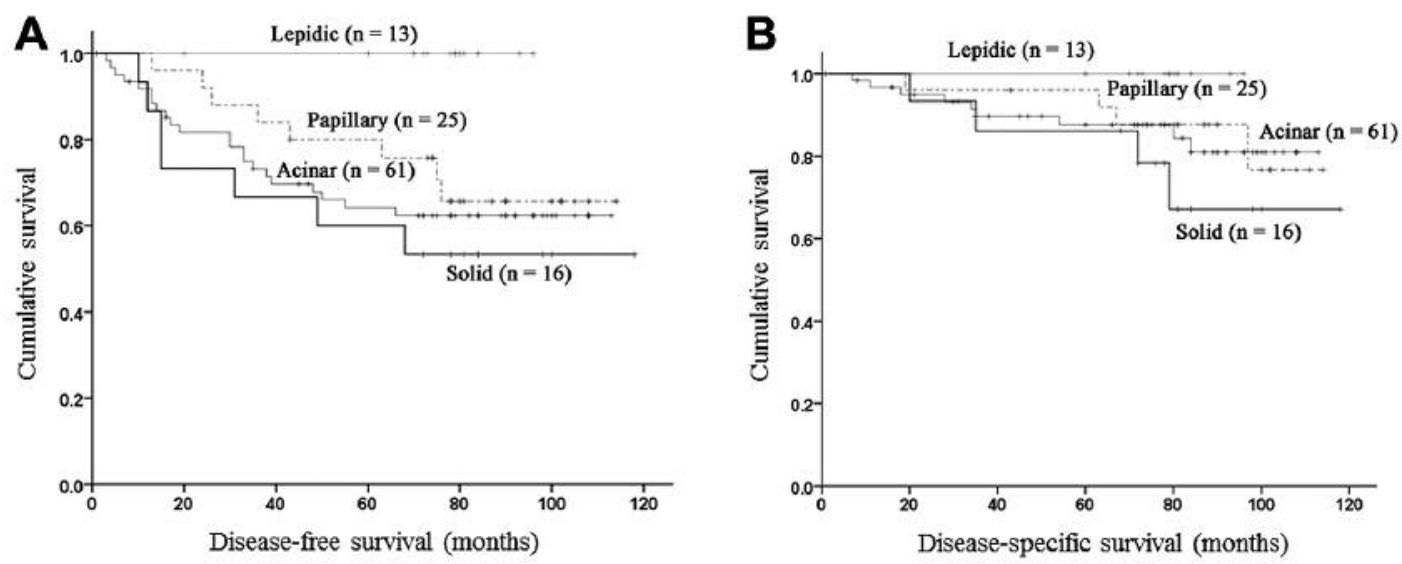

Figure 1. Kaplan-Meier curves of disease-free $(A)$ and disease-specific $(B)$ survival according to the predominant subtype according to the American Thoracic Society and the European Respiratory Society classification.
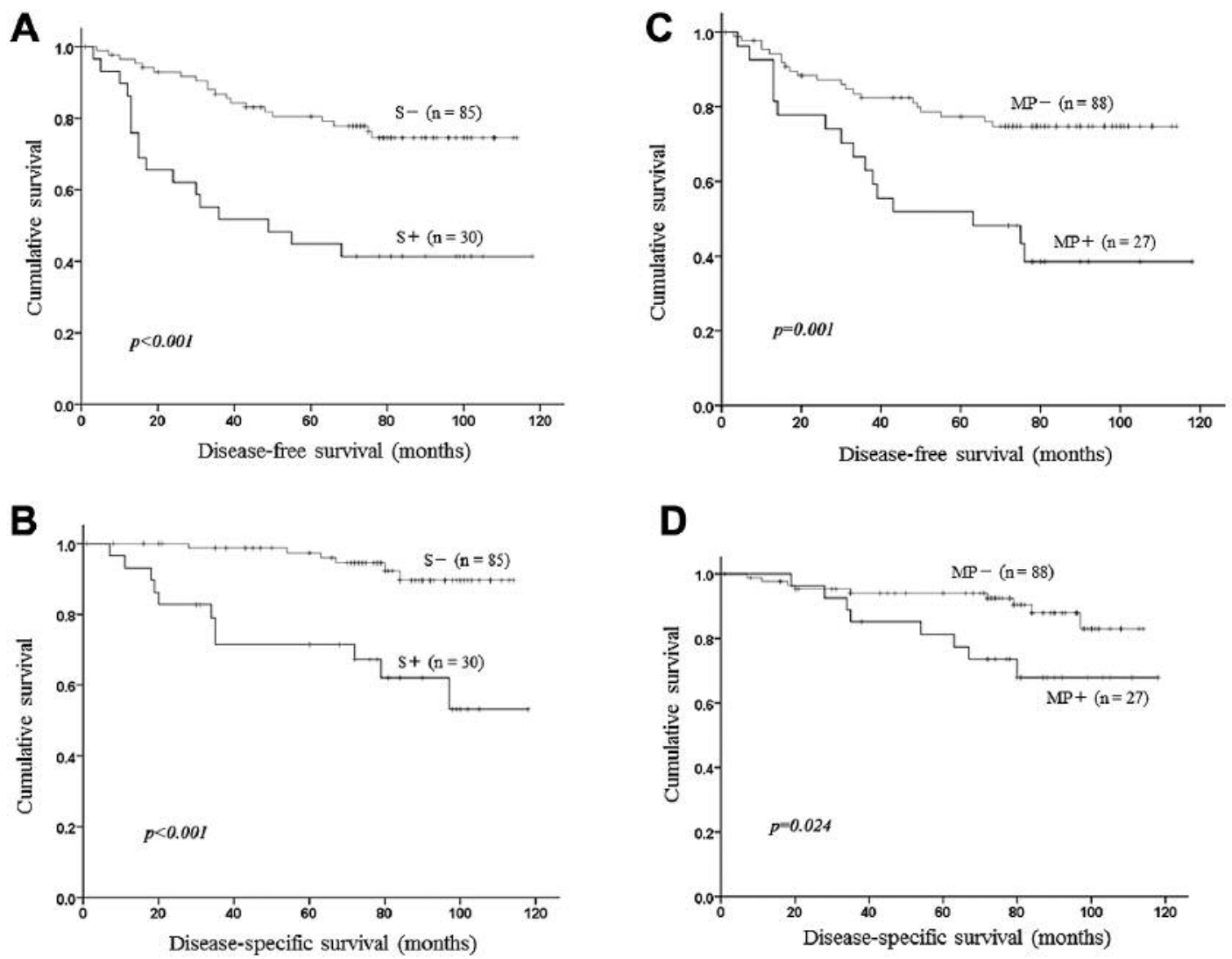

Figure 2. Kaplan-Meier curves of disease-free $(A, C)$ and disease-specific $(B, D)$ survival according to the presence of solid $(S+)(A, B)$ and micropapillary $(M P+)(C, D)$ components.

the same as those of the American cohort except for the micropaillary-predominant pattern.

In contrast, a Japanese cohort of 347 patients with stage IA lung adenocarcinoma (16) had a low frequency of the micropaillary-predominant pattern (1.7\%). The difference in the sample size may be partly responsible for the discrepant results among the past and present studies. An association between the prognosis and the predominant subtype has 

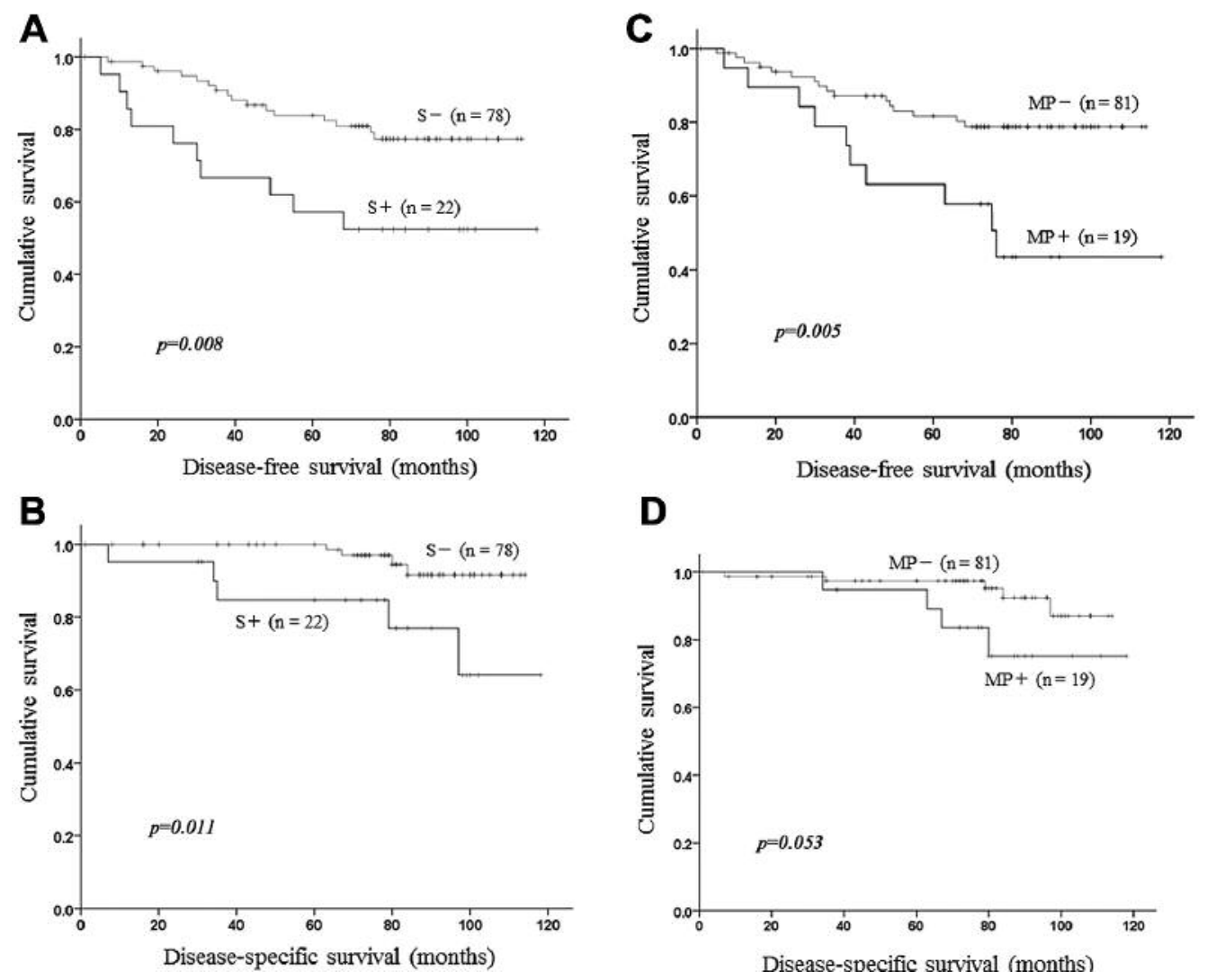

Figure 3. Kaplan-Meier curves of disease-free $(A, C)$ and disease-specific $(B, D)$ survival according to the presence of solid $(S+)(A, B)$ and micropapillary $(\mathrm{MP}+)(C, D)$ components in patients with stage I lung adenocarcinoma.
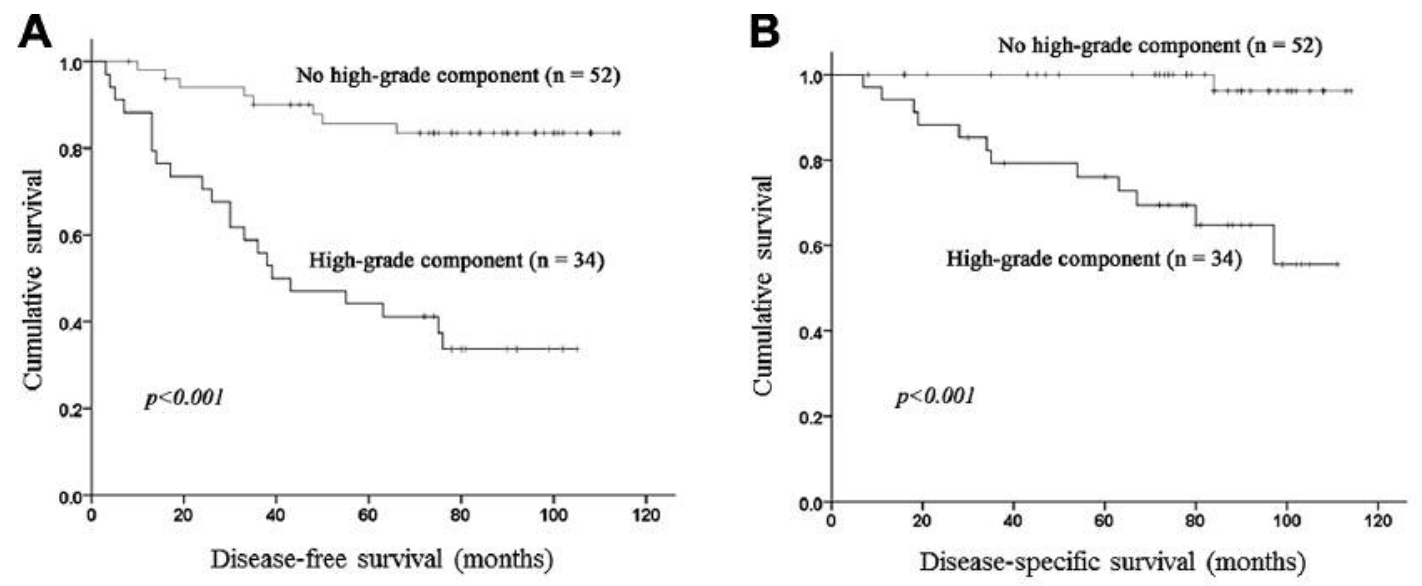

Figure 4. Kaplan-Meier curves of disease-free (A) and disease-specific (B) survival according to the presence of high-grade [solid (S+) and/or micropapillary $(M P+)]$ components in the 86 patients of the acinar-and papillary-predominant subgroups.

been validated according to the IASLC/ATS/ERS classification, and many studies have reported that both the solid-predominant and micropapillary-predominant subtypes conferred a poor prognosis compared to the other subtypes (4-10).
However, few studies have reported the clinical significance of a minor (non-predominant) component of the solid or micropapillary pattern constituting $\geq 1 \%$ of the entire tumor (11-13). Of those studies, only one investigated patients with invasive lung adenocarcinoma measuring 
Table II. Multivariate analysis of various prognostic factors in 115 patients with invasive lung adenocarcinoma measuring $\leq 3 \mathrm{~cm}$.

\begin{tabular}{|c|c|c|c|c|c|c|}
\hline \multirow[t]{2}{*}{ Prognostic factor } & \multicolumn{3}{|c|}{ Disease-free survival } & \multicolumn{3}{|c|}{ Disease-specific survival } \\
\hline & HR & $95 \% \mathrm{CI}$ & $p$-Value & HR & $95 \% \mathrm{CI}$ & $p$-Value \\
\hline Age ( $>60$ vs $\leq 60$ years) & 2.279 & $0.815-6.370$ & 0.116 & 2.497 & $0.632-9.859$ & 0.191 \\
\hline Gender (male vs. female) & 1.062 & $0.489-2.305$ & 0.88 & 1.321 & $0.466-3.746$ & 0.601 \\
\hline Pleural invasion (present $v s$. absent) & 2.924 & $1.311-6.524$ & 0.009 & 2.727 & $0.851-8.734$ & 0.091 \\
\hline Pathological stage (I vs. II-IIIA) & 2.775 & $1.233-6.243$ & 0.014 & 5.443 & $1.627-18.206$ & 0.006 \\
\hline Solid component (present $v s$. absent) & 2.705 & $1.330-5.504$ & 0.006 & 5.090 & $1.764-14.686$ & 0.003 \\
\hline Micropapillary component (present $v s$. absent) & 2.504 & $1.225-5.119$ & 0.012 & 1.586 & $0.505-4.982$ & 0.430 \\
\hline
\end{tabular}

HR, Hazard ratio; CI, confidence interval.

Table III. Multivariate analysis of various prognostic factors in 86 patients in acinar-and papillary-predominant subgroups.

\begin{tabular}{|c|c|c|c|c|c|c|}
\hline \multirow[t]{2}{*}{ Prognostic factors } & \multicolumn{3}{|c|}{ Disease-free survival } & \multicolumn{3}{|c|}{ Disease-specific survival } \\
\hline & HR & $95 \% \mathrm{CI}$ & $p$-Value & HR & $95 \% \mathrm{CI}$ & $p$-Value \\
\hline Age ( $>60$ vs $\leq 60$ years) & 3.031 & $0.932-9.864$ & 0.065 & 4.737 & $0.953-23.557$ & 0.057 \\
\hline Gender (male $v s$. female) & 0.745 & $0.311-1.784$ & 0.509 & 0.526 & $0.166-1.670$ & 0.276 \\
\hline Pleural invasion (present $v s$. absent) & 2.653 & $1.181-5.963$ & 0.018 & 2.444 & $0.704-8.483$ & 0.159 \\
\hline Pathological stage (I vs. II-IIIA) & 3.066 & $1.306-7.197$ & 0.01 & 5.449 & $1.532-19.377$ & 0.009 \\
\hline High-grade component (present $v s$. absent) & 5.519 & 2.344-12.995 & $<0.001$ & 17.963 & $2.271-142.062$ & 0.006 \\
\hline
\end{tabular}

HR, Hazard ratio; CI, confidence interval.

$\leq 3 \mathrm{~cm} \mathrm{(13),} \mathrm{and} \mathrm{no} \mathrm{studies} \mathrm{investigated} \mathrm{the} \mathrm{clinical}$ significance in patients with stage I lung adenocarcinomas. We, therefore, focused on the clinical significance of a solid or micropapillary component constituting $\geq 1 \%$ of the entire tumor in lung adenocarcinomas measuring $\leq 3 \mathrm{~cm}$ or stage I. The selection of tumors measuring $\leq 3 \mathrm{~cm}$ in our study enabled the pathological examination of whole tumors and reduced the likelihood of overlooking a minor component ( $\leq 5 \%$ of the entire tumor).

Cha et al. reported that the solid subtype $(\geq 1 \%)$ had limited influence on the overall survival (OS) only when it co-existed with the micropapillary subtype, and that the presence of micropapillary subtype was the single prognostic factor for OS (13). In turn, Zhao et al. reported that minor components ( $>5 \%$, but not predominant) of micropapillary or solid subtypes were correlated with lymph-node metastasis and poor prognosis (DFS and OS) (10). In our present study, both solid $(\geq 1 \%)$ and micropapillary $(\geq 1 \%)$ components were independent indicators of worse prognosis (DFS and DSS) in all cases, and in the stage I cases. Although most studies of lung cancer use OS for the survival analysis, a high percentage of deaths not related to cancer among patients with stage I adenocarcinoma has been reported (4).
The differences in the clinical significance of the solid component between our study and that reported by Cha et al. may, in part, be responsible for the difference in the OS and DSS values. Moreover, the difference in the percentage of patients who had neither a solid nor micropapillary component between our cohort and Cha et al.'s (56.5\% vs. $17.0 \%$ ) may contribute to the differences in the clinical significance of the solid component.

In the present study, there was no patient with a solid or micropapillary component in the lepidic-predominant subgroup; we, therefore, focused on the clinical impact of high-grade components (solid and/or micropapillary component) in patients with acinar- and papillary-predominant subgroups. To our knowledge, the present report is the first to show that the presence of high-grade components are independent indicators of poor prognosis in patients with acinar- and papillary-predominant lung adenocarcinoma.

The limitations of the present study are the small number of patients and the study's retrospective nature. The patients' status regarding whether they received adjuvant therapies after relapse (especially molecular targeted therapy) was not taken into consideration in our survival analysis. Moreover, our cohort included cases with segmentectomy or wedge resection although the ratio of solid or micropapillary 
components was not significantly different compared to lobectomy cases. Despite these limitations, our present findings demonstrated that high-grade components are independent indicators of shorter DFS in the acinar- and papillary-predominant subgroups.

It has been reported that the DFS more accurately reflects the biological behavior of tumors compared to the OS in stage I lung adenocarcinoma (4). Therefore, our present findings could be a first step toward further investigations of larger numbers of patients in acinar- and papillarypredominant lung adenocarcinoma subgroups.

In conclusion, the detection of solid or micropapillary components $(\geq 1 \%)$ in addition to the IASLC/ATS/ERS classification could be useful for the further stratification of patients and for decision-making regarding therapeutic strategies.

\section{Acknowledgements}

The Authors thank Kazuo Yashima and Kazuko Fukushima for their excellent technical assistance with the processing of the pathological specimens.

\section{References}

1 Jemal A, Bray F, Center MM, Ferlay J, Ward E and Forman D: Global cancer statistics. CA Cancer J Clin 61: 69-90, 2011.

2 Travis WD, Brambilla E, Burke AP, Marx A and Nicholson AG: WHO Classification of Tumours of the Lung, Pleura, Thymus and Heart, Fourth Edition. IARC, Lyon, 2015.

3 Travis WD, Brambilla E, Noguchi M, Nicholson AG, Geisinger KR, Yatabe Y, Beer DG, Powell CA, Riely GJ, Van Schil PE, Garg K, Austin JH, Asamura H, Rusch VW, Hirsch FR, Scagliotti G, Mitsudomi T, Huber RM, Ishikawa Y, Jett J, Sanchez-Cespedes M, Sculier JP, Takahashi T, Tsuboi M, Vansteenkiste J, Wistuba I, Yang PC, Aberle D, Brambilla C, Flieder D, Franklin W, Gazdar A, Gould M, Hasleton P, Henderson D, Johnson B, Johnson D, Kerr K, Kuriyama K, Lee JS, Miller VA, Petersen I, Roggli V, Rosell R, Saijo N, Thunnissen E, Tsao $\mathbf{M}$ and Yankelewitz D: International Association for the Study of Lung Cancer/American Thoracic Society/European Respiratory Society. International multidisciplinary classification of lung adenocarcinoma. J Thorac Oncol 6(2): 244-285, 2011.

4 Yoshizawa A, Motoi N, Riely GJ, Sima CS, Gerald WL, Kris MG, Park BJ, Rusch VW and Travis WD: Impact of proposed IASLC/ATS/ERS classification of lung adenocarcinoma: prognostic subgroups and implications for further revision of staging based on analysis of 514 stage I cases. Mod Pathol 24: 653-664, 2011.

5 Russell PA, Wainer Z, Wright GM, Daniels M, Conron M and Williams RA: Does lung adenocarcinoma subtype predict patient survival?: A clinicopathologic study based on the new International Association for the Study of Lung Cancer/ American Thoracic Society/European Respiratory Society international multidisciplinary lung adenocarcinoma classification. J Thorac Oncol 6(9): 1496-1504, 2011.
6 Warth A, Muley T, Meister M, Stenzinger A, Thomas M, Schirmacher P, Schnabel PA, Budczies J, Hoffmann H and Weichert W: The novel histologic International Association for the Study of Lung Cancer/American Thoracic Society/European Respiratory Society classification system of lung adenocarcinoma is a stage-independent predictor of survival. J Clin Oncol 30: 1438-1446, 2012.

7 Hung JJ, Yeh YC, Jeng WJ, Wu KJ, Huang BS, Wu YC, Chou TY and Hsu WH: Predictive value of the International Association for the Study of Lung Cancer/American Thoracic Society/European Respiratory Society international multidisciplinary classification of lung adenocarcinoma in tumor recurrence and patient survival. J Clin Oncol 2: 23572364, 2014.

8 Hung JJ, Jeng WJ, Chou TY, Hsu WH, Wu KJ, Huang BS and Wu YC: Prognostic value of the new International Association for the Study of Lung Cancer/American Thoracic Society/European Respiratory Society lung adenocarcinoma classification on death and recurrence in completely resected stage I lung adenocarcinoma. Ann Surg 258: 1079-1086, 2013.

9 Solis LM, Behrens C, Raso MG, Lin HY, Kadara H, Yuan P, Galindo H, Tang X, Lee JJ, Kalhor N, Wistuba II and Moran CA: Histologic patterns and molecular characteristics of lung adenocarcinoma associated with clinical outcome. Cancer 118 : 2889-2899, 2012.

10 Zhao Y, Wang R, Shen X, Pan Y, Cheng C, Li Y, ShenL, Zang Y, Li H, Zheng D, Ye T, Zheng S, Sun Y and Chen H: Minor components of micropapillary and solid subtypes in lung adenocarcinoma are predictors of lymph node metastasis and poor prognosis. Ann Surg Oncol 23(6): 2099-2105, 2016.

11 Lee G, Lee HY, Jeong JY, Han J, Cha MJ, Lee KS,Kim J and Shim YM: Clinical impact of minimal micropapillary pattern in invasive lung adenocarcinoma. Prognostic significance and survival outcomes. Am J Surg Pathol 39: 660-66, 2014.

12 Tsutsumida H, Nomoto M, Goto M, Kitajima S, Kubota I, Hirotsu Y, Wakimoto J, Hollingsworth MA and Yonezawa S: A micropapillary pattern is predictive of a poor prognosis in lung adenocarcinoma, and reduced surfactant apoprotein A expression in the micropapillary pattern is an excellent indicator of a good prognosis. Mod Pathol 20: 638-647, 2007.

13 Cha MJ, Lee HY, Lee KS, Jeong JY, Han J, Shim YM and Hwang HS: Micropapillary and solid subtypes of invasive lung adenocarcinoma: Clinical predictors of histopathology and outcome. J Thorac Cardiovasc Surg 147: 921-928, 2014.

14 Asamura H, Goya T, Koshiishi Y, Sohara Y, Eguchi K, Mori M, Nakanishi Y, Tsuchiya R, Shimokata K, Inoue H, Nukiwa T, Miyaoka E; Japanese Joint Committee of Lung Cancer Registry: A Japanese Lung Cancer Registry study: prognosis of 13,010 resected lung cancers. J Thorac Oncol 3(1): 46-52, 2008.

15 Kelsey CR, Higgins KA, Peterson BL, Chino JP, Marks LB, D'Amico TA and Varlotto JM: Local recurrence after surgery for non-small cell lung cancer: a recursive partitioning analysis of multi-institutional data. J Thorac Cardiovasc Surg 146(4): 768773, 2013.

16 Murakami S, Ito H, Tsubokawa N, Mimae T, Sasada S, Yoshiya T, Miyata Y, Yokose T, Okada M and Nakayama H: Prognostic value of the new IASLC/ATS/ERS classification of clinical stage IA lung adenocarcinoma. Lung Cancer 90(2): 199-204, 2015. 
17 Ujiie H, Kadota K, Chaft JE, Buitrago D, Sima CS, Lee MC, Huang J, Travis WD, Rizk NP, Rudin CM, Jones DR and Adusumilli PS: Solid predominant histologic subtype in resected stage I lung adenocarcinoma is an independent predictor of early, extrathoracic, multisite recurrence and of poor postrecurrence survival. J Clin Oncol 33(26): 2877-2884, 2015.

$18 \mathrm{Xu} \mathrm{S}, \mathrm{Xi}$ J, Jiang W, Lu S and Wang Q: Solid component and tumor size correlate with prognosis of stage IB lung adenocarcinoma. Ann Thorac Surg 99: 961-967, 2015.

19 Goldstraw P, Crowley J, Chansky K, Giroux DJ, Groome PA, Rami-Porta R, Postmus PE, Rusch V and Sobin L: The IASLC Lung Cancer Staging Project: proposals for the revision of the TNM stage groupings in the forthcoming (seventh) edition on the TNM classification of malignant tumours. J Thorac Oncol 2: 706-714, 2007.
20 Thunnissen E, Beasley MB, Borczuk AC, Brambilla E, Chirieac LR, Dacic S, Flieder D, Gazdar A, Geisinger k, Hasleton P, Ishikawa Y, Kerr KM, Lantejoul S, Matsuno Y, Minami Y, Moreira Al, Motoi N, Nicholson AG, Noguchi M, Nonka D, Pelosi G, Petersen I, Rekhtman N, Roggli V, Travis WD, Tsao MS, Wistuba I, Xu H, Yatabe Y, Zakowski M, Witte B and Kuik DJ: Reproducibility of histopathological subtypes and invasion in pulmonary adenocarcinoma: An international interobserver study. Mod Pathol 25(12): 1574-1583, 2012.

Received June 21, 2016

Revised July 10, 2016

Accepted July 15, 2016 